\title{
Enhance of the polystyrene based plastic scintillator radiation hardness; using fluorine-derivatives of 3 -hydroxyflavone
}

\author{
Yu.A.Gurkalenko, P.M.Zhmurin, \\ V.M.Pereymak, D.A.Yelisieiev, O.V.Yelisieieva \\ Institute for Scintillation Materials, STC "Institute for Single Crystals", \\ National Academy of Sciences of Ukraine, 60 Nauky Ave., \\ 61001 Kharkiv, Ukraine
}

Received March 26, 2018

\begin{abstract}
New fluorine-derivatives of 3-hydroxyflavone (3HF) are synthesized. Their spectral luminescent properties are investigated. A range of plastic scintillators (PS), which contain fluorine-derivatives of 3-hydroxyflavone as the activation dopant, is obtained. Influence of replace of hydrogen atoms with fluorine atoms in 3-HF molecules on the PS radiation hardness is studies.
\end{abstract}

Keywords: 3-hydroxyflavone, activator, plastic scintillator, radiation hard.

Синтезированы фторпроизводные 3-гидроксифлавона (3HF). Исследованы их спектрально-люминесцентные свойства. Получен ряд полистирольных пластмассовых сцинтилляторов, содержащих в качестве активирующей добавки фторпроизводные 3-гидроксифлавона. Изучено влияние замены водорода атомами фтора в молекулах $3 \mathrm{HF}$ на радиационную стойкость ПС.

Підвищення радіаційної стійкості полістирольних пластмасових сцинтиляторів 3 фторпохідними 3-гідроксифлавону. Ю.А.Гуркаленко, П.М.Жлурін, В.М.Перейлак, Д.А.Єлісєєв, О.В.Єлісєєва.

Синтезовано фторпохідні 3-гідроксифлавону (3HF). Досліджено іх спектральнолюмінесцентні властивості. Отримано низку полістирольних пластмасових сцинтиляторів, що містять в якості активуючої добавки фторпохідні 3-гідроксифлавону. Вивчено вплив заміни водню атомами фтору у молекулах $3 \mathrm{HF}$ на радіаційну стійкість ПС.

\section{Introduction}

Development of experimental technics in the high-energy physics causes increase of requirements to the detector scintillation materials resistance to the high irradiation doses.

At this time on the Large Hadron Collider (CERN, Switzerland) at collision of two proton beams, the energy of $15.4 \mathrm{TeV}$ $\left(15.4 \cdot 10^{12} \mathrm{eV}\right)$ originates at the integral luminosity $1.7 \cdot 10^{34} \mathrm{~cm}^{-2} \mathrm{c}^{-1}$ [1]. Wherein the total radiation dose, accumulated by the nearest to the beam axis PS, can reach $10 \mathrm{Mrad}$ for 10 years of detector operation [2].
After planned upgrade in 2016-2018 years, the energy of protons in the LHC beam will double, and the luminosity will increase by the order of magnitude [3]. Accordingly, the total irradiation dose, obtained by the installed detectors, will growth by the order. However, traditional commercially available PS usually do not meet new requirements of the radiation hardness. The light yield half attenuation doses $\left(D_{1 / 2}\right)$ of commercial PS SCSN-81T, BC-408 and UPS923A are within limits 1-2 Mrad, $D_{1 / 2}$ of radiation hard PS UPS-98RH 5.1 Mrad [4]. 
<smiles>O=c1c(O)c(-c2ccccc2)oc2ccccc12</smiles>

Fig. 1. Structural formula of 3-hydroxy-2phenyl-4H-chromen-4-one (3HF) molecule.

One of the causes of PS light yield decrease under high-energy particles irradiation is associated with transfer of localized excitation energy to the hydrogen atom, what leads to it's separation from macromolecule with the formation of a radical. The last is able to form new chemical compositions, which able to absorb optical radiation. Experiments show, that under high-energy irradiation in PS polystyrene base absorption centers, which effectively absorb within the diapason from 300 to $480 \mathrm{~nm}$, are formed [5].

Since the main absorption and luminescent bands of PS activation dopants are located in this diapason, generation of such absorbing centers under irradiation leads to significant degradation of the PS scintillation parameters. Thus, one of the ways of radiation hardness increase in plastic scintillator is connected with shift of the activator molecule main luminescence band to more long-wave diapason, where scintillation signal absorption will be insignificant. Actually, in our work [6] it was shown, that use of 3-hydroxyflavone (3HF) as an activator (Fig. 1), with the located in range of $530 \mathrm{~nm}$ luminescent maximum, allows to in-

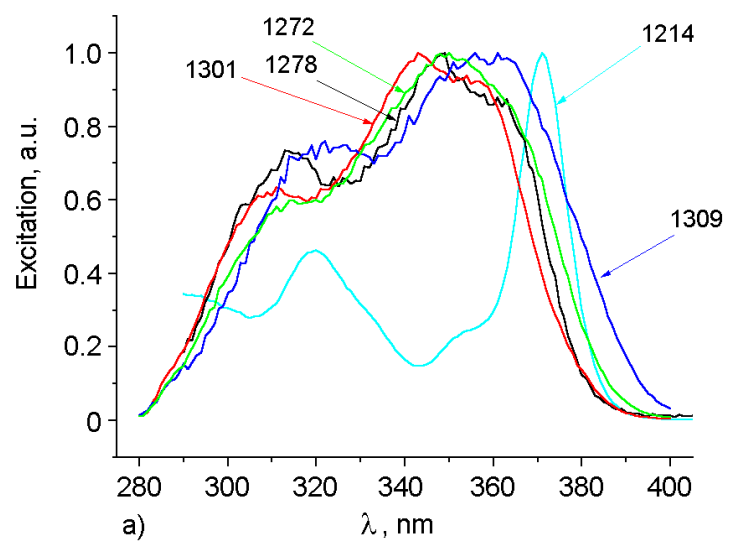

crease the radiation hardness of plastic scintillator several times.

However, as a result of irradiation, not only the optical parameters of the plastic scintillator polymeric base degrade, but also a large extent the activator molecules destruction occurs. Thus, it is needed to find ways of activator molecules modification, increasing their radiation stability. And one of the ways can be replacement of hydrogen atoms in $3 \mathrm{HF}$ molecules with fluorine atoms.

Thus, the goal of this work is study of influence of replacement of hydrogen atoms in $3 \mathrm{HF}$ molecules with fluorine on the radiation hardness of polystyrene based plastic scintillators activated with modified $3 \mathrm{HF}$ molecules.

\section{Experimental}

Fluorine derivatives of 3-hydroxyflavone were obtained by the Algar-Flynn-Oyamada reaction by oxidation of o-hydroxyphenylstyrylketones to flavones with hydrogen peroxide [7]. For this, equimolecular amounts of corresponding fluorinated benzaldehydes and o-hydroxyacetophenones were dissolved in ethanol and mixed with aqueous sodium hydroxide solution. Obtained chalcone was oxidized with $30 \% \mathrm{hy}$ drogen peroxide in alkaline medium with subsequent neutralization by dilute mineral acid. Obtained fluorine derivatives of 3-hydroxyflavone were purified by chromatography on silica gel.

As a result, the range of 3-hydroflavones with a different number of fluorine atoms was synthesized. Structural formulas, denominations and numeric conventions (codes) of obtained substances are presented in Table 1.

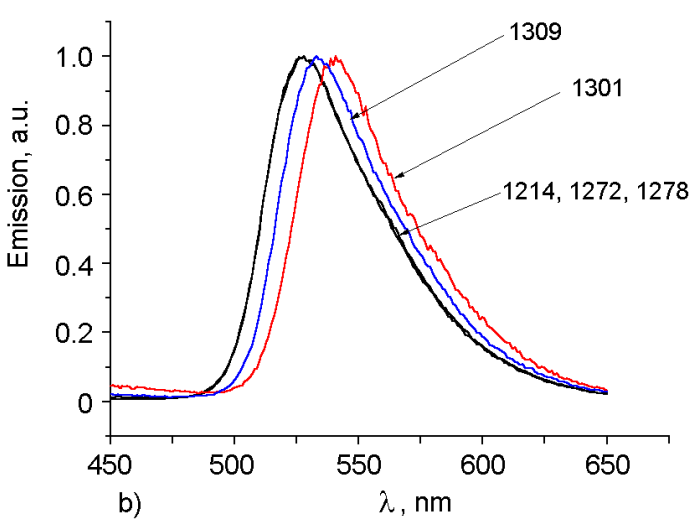

Fig. 2. Excitation spectra (a) and luminescence (b) of $3 \mathrm{HF}$ molecules and its derivatives in toluene solution (the concentration $10^{-5} \mathrm{~mol} / \mathrm{l}$ ). 
Table 1. Codes, structural formulas and denominations of 3HF fluorine derivatives

\begin{tabular}{|c|c|c|}
\hline Code & Structural formula & Name of fluorine derivatives $3 \mathrm{HF}$ \\
\hline 1214 & & 3-hydroxy-2-phenyl-4H-chromen-4-one \\
\hline 1272 & & 2-(4-fluorophenyl)-3-hydroxy-4H-chromen-4-one \\
\hline 1278 & & 6-fluoro-3-hydroxy-2-phenyl-4H-chromen-4-one \\
\hline 1280 & & 6-fluoro-2-(4-fluorophenyl)-3-hydroxy-4H-chromen-4-one \\
\hline 1301 & & 2-(3,4-difluorophenyl)-6,7-difluoro-3-hydroxy-4H-chromen-4-one \\
\hline 1309 & & 2-(3,4-difluorophenyl)-6,8-difluoro-3-hydroxy-4H-chromen-4-one \\
\hline
\end{tabular}

The synthesized 3HF fluorine derivatives were used as activation dopant of plastic scintillator polystyrene base. The PS samples were obtained by bulk polymerization. For this fluorescent dopants in amount of 2.0 wt. $\%$ were placed in glass vials and dissolved in appropriate amount of styrene. The reaction mass was purged with argon for $15 \mathrm{~min}$ and polymerized at the temperature of $150^{\circ} \mathrm{C}$ for 3 days. From obtained bars, samples were cut with the shape of cylinders of $16 \mathrm{~mm}$ diameter and of $10 \mathrm{~mm}$ height, and then polished to optical grade.

The spectral luminescent properties of the samples were measured on a spectrofluorimeter Horiba Jobin Yvon Fluoromax-4.

To measure the light output, the PS samples were mounted on a photomultiplier through immersion fluid and irradiated by monoenergetic conversion electrons of a ra- diation source Bi-207. The light output was determined by position of the peak maximum of electrons with energy of $975 \mathrm{keV}$.

The time characteristics were determined by the delayed coincidence method with two-channel system with two PMT Hamamatsu 9800 with Start and Stop channels. To measure the time characteristics of the PS used an electron source Sr-90. As a start pulse, a Cerenkov radiation signal from a pure polymethylmethacrylate sample was used.

To determine the radiation hardness, the PS samples were placed in air medium into radiation field of a Co-60 source with the dose rate of $50 \mathrm{rad} / \mathrm{min}$ and were irradiated to the obtained dose of $8 \mathrm{Mrad}$. Measurements of the light output of the samples were performed right away after the irradiation. 

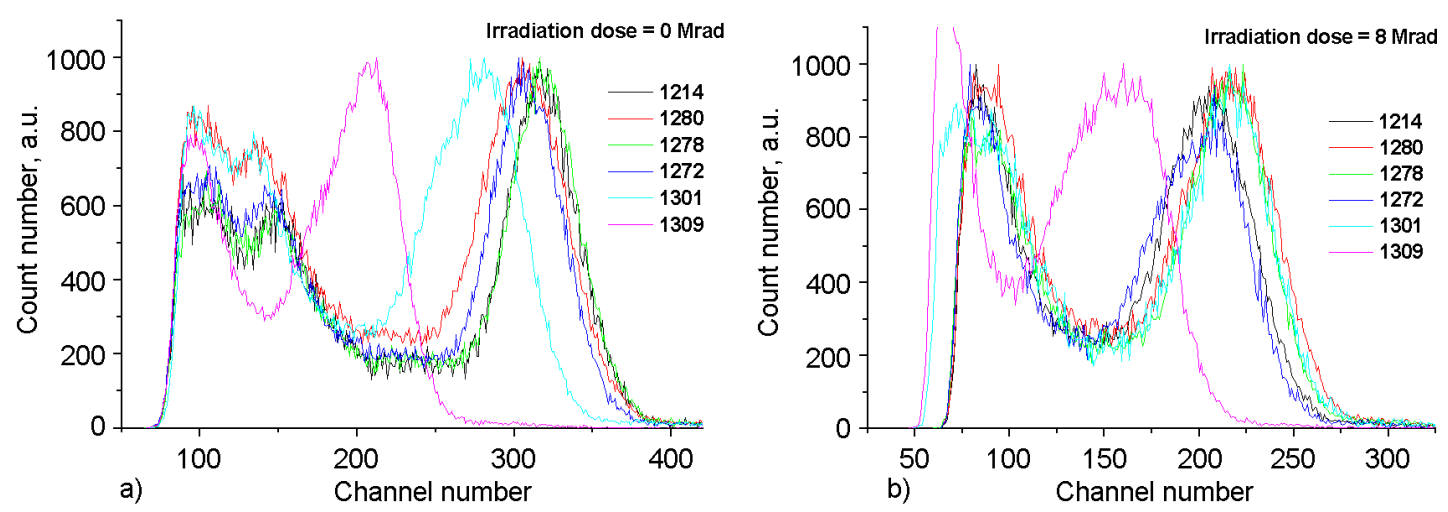

Fig. 3. Energy spectra of the polystyrene scintillation compositions, containing 2 wt. $\% 3 \mathrm{HF}$ fluorine-derivatives, before (a) and after (b) irradiation.

\section{Results and discussion}

Molecules of 3HF have the large Stocks shift due to proton transfer in excited state. The absorption band maximum of $3 \mathrm{HF}$ is located in region of $360 \mathrm{~nm}$, at the same time the luminescence band has the maximum at $530 \mathrm{~nm}$. In Fig. 2 the excitation (a) and luminescence (b) spectra of $3 \mathrm{HF}$ molecules and its derivatives in toluene solution.

In the $3 \mathrm{HF}$ fluorine derivatives excitation spectra, growth of the short-wavelength excitation band intensity relatively to the initial 3HF specter (Fig. 3a).

In Fig. $3 \mathrm{~b}$ it is seen, that substitution of one or two hydrogen atoms by fluorine into $3 \mathrm{HF}$ molecule practically doesn't affect character of its luminescent spectrum. The luminescent spectrum maximum begins to shift somewhat into the long-wavelength region only after substitution of four hydrogen atoms with fluorine.

Thus, location of the 3HF fluorine derivatives main luminescent maximum in the region of $530 \mathrm{~nm}$, as in initial molecules, provides decrease of loses through capture on traps, generated at irradiation of polystyrene.

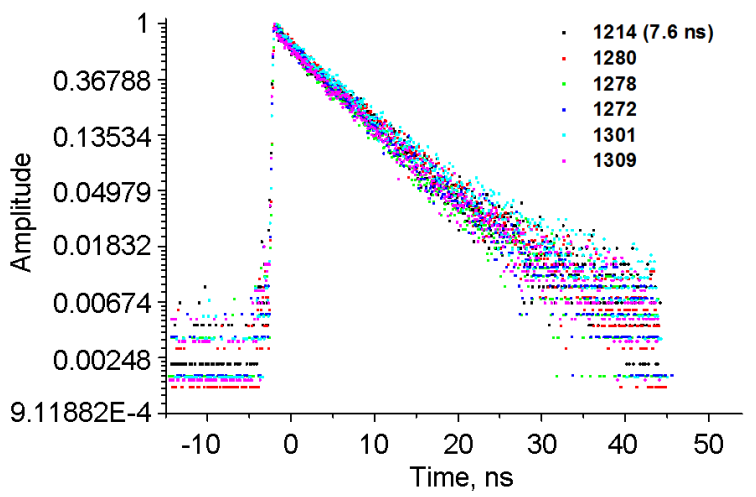

Fig. 4. The kinetic specters of the polystyrene compositions, containing $3 \mathrm{HF}$ fluorinederivatives.

For determination of the radiation hardness of the obtained PS, their light yield measurement was performed before and after irradiation with the dose of $8 \mathrm{Mrad}$ (Fig. 3).

In Table 2 PS compositions, their light yield before $\left(L_{0}\right)$ and after $(L)$ irradiation with the dose of $8 \mathrm{Mrad}$, and also light yields ratio $\left(L / L_{0}\right)$, which characterizes degree of irradiation influence on the PS scintillation characteristics. The light yield half

Table 2. The scintillation characteristics of the polystyrene PS, containing 2 wt. $\% 3 \mathrm{HF}$ derivatives, before and after irradiation with the dose of $8 \mathrm{Mrad}$

\begin{tabular}{|c|c|c|c|c|c|}
\hline Composition PS & $L_{0}$, ch No. & $L, \operatorname{ch}$ No. & $L / L_{0}$ & $D_{1 / 2}$, Mrad & $\begin{array}{c}\text { Radiation } \\
\text { hardness, \% }\end{array}$ \\
\hline 2 wt $\%(1214)+P S$ & 315 & 203 & 0.64 & 12.6 & 100.0 \\
\hline 2 wt $\%(1272)+P S$ & 306 & 209 & 0.68 & 14.5 & 115.0 \\
\hline 2 wt $\%(1278)+\mathrm{PS}$ & 315 & 214 & 0.68 & 14.3 & 113.5 \\
\hline 2 wt $\%(1280)+P S$ & 304 & 214 & 0.7 & 15.8 & 125.4 \\
\hline $2 \mathrm{wt} \%(1301)+\mathrm{PS}$ & 280 & 214 & 0.76 & 20.6 & 163.5 \\
\hline 2 wt $\%(1309)+P S$ & 209 & 161 & 0.77 & 21.3 & 169.0 \\
\hline
\end{tabular}


attenuation dose was used as the criterion of radiation hardness. The light yield half attenuation dose values $\left(D_{1 / 2}\right)$ were obtained by extrapolation of present data.

It is seen in the obtained data, the new scintillation compositions demonstrate the higher radiation hardness relatively to plastic scintillators, in which content initial 3-hydroxyflavone (1214) as activator. Replacement of hydrogen with fluorine atoms leads to increase of the radiation hardness of activated with them plastic scintillators. Depending on position and quantity of fluorine atoms in the $3 \mathrm{HF}$ molecule, we managed to increase the radiation hardness in the range from 15 to $69 \%$.

In addition, investigation of the temporal characteristics of the obtained scintillators was performed. It has been shown, that they have the practically equal scintillation pulse rise times, which amount 0.9 ns (Fig. 5). Such value is typical for polystyrene-based plastic scintillators, because it basically connected with the time of recombination of charges in the track, created while high-energy particle flight. More detail measurements of the temporal characteristics are presented in our work [8].

It is seen in Fig. 4, modification of 3-hydroxyflavone molecule doesn't lead to change of the scintillation pulse decay time, which is equal to $7.6 \mathrm{~ns}$. It is necessary to notice, that the decay time do not take change after irradiation with the dose of 8 Mrad. They still have the exponential character and the decay time does not change. This means, that after irradiation, nonradiative quenching of activator molecules luminescence does not occur.

\section{Conclusions}

As a result of the performed investigations it was shown, that modification of 3-hydroxyflavone molecules by input fluorine atoms leads to the next effects:

Substitution of one or two hydrogen atoms by fluorine in any part of the $3 \mathrm{HF}$ molecule practically does not affect the nature of the luminescence spectra. The luminescence maximum begins to shift to the long-wavelength region by 5-10 $\mathrm{nm}$ only after the replacement of four hydrogen atoms by fluorine. In the excitation spectra of all fluorine derivatives, an increase in the intensity of the short-wave band is observed.

The temporal characteristics of the plastic scintillators don't undergo changes, wherein the scintillation pulse decay time for all compounds is equal to $7.6 \mathrm{~nm}$.

Replacement of hydrogen with fluorine atoms in molecules of 3-hydroxyflavone leads to increase of the radiation hardness of plastic scintillators, activated with them. Depending on position and quantity of fluorine atoms in $3 \mathrm{HF}$ molecule, we managed to achieve increase of the plastic scintillator radiation hardness in the range from 15 to $69 \%$ relatively to PS, containing initial 3-hydroxyflavone. This result allows to significantly increase the exploitation time of PS in radiation load conditions.

\section{References}

1. Desigh Study of Large Hadron Collider, CERN 91-03, Geneva, CERN (1991).

2. The Level-1 Trigger Technical Design Report, CERN/LHCC-2000-038, CMS TDR 6.1, 15 December 2000, p.40.

3. O.Bruning, R.Cappiz et al. R. LHC Project Report 626. LHC Luminosity and Energy Up grade: A Feasibility Study, https://cds.cern.ch/ record/601847/files/lhc-project-report-626.pdf

4. V.G.Senchishin, V.N.Lebedev, A.F.Adadurov et al., Functional Materials, 10, 281 (2003).

5. A.D.Bross, A.Pla-Dalmau, Nucl.Inst. Meth. Phys. Res. A, 327, 337 (1993).

6. Yu.A. Gurkalenko, P.N.Zhmurin, V.N.Lebedev et al., Functional Materials, 23, 40 (2016).

7. B.S.Jayashree, N.F.Anjum, Y.Nayak et al., Pharmacologyonline, 3, 586 (2008).

8. Yu.A.Gurkalenko, D.A.Eliseev, P.N.Zhmurin et al., Functional Materials, 24, 244 (2017). 